\title{
QUEFTS Model-based Estimation of the Nutrient Requirements and Fertilizer Recommendation for Chinese Onion
}

\author{
Jianlin Wei \\ Institute of Agricultural Resources and Environment, Shandong Academy \\ of Agricultural Sciences, Jinan, Shandong 250100, China
}

\author{
Shutian Li, Ping He, and Xinpeng $\mathrm{Xu}$ \\ Institute of Agricultural Resources and Agricultural Regional Planning, \\ Chinese Academy of Agricultural Sciences, Beijing 100081, China
Deshui Tan, Yan Li, and Guosheng Li
Institute of Agricultural Resources and Environment, Shandong Academy of Agricultural Sciences, Jinan, Shandong 250100, China

Yuesheng Guo

Shandong Provincial Soil and Fertilizer General Station, Jinan, Shandong 250100, China

\section{Rongzong Cui \\ Institute of Agricultural Resources and Environment, Shandong Academy of Agricultural Sciences, Jinan, Shandong 250100, China}

Additional index words. Chinese onion, NPK requirement, QUEFTS model, yield response, agronomic efficiency

\begin{abstract}
Accurate estimation of the nutrient requirements of Chinese onion is essential to increase its nutrient utilization efficiency and yield. In this study, the yield and nutrient uptake data were collected from major Chinese onion growing regions during 2001 to 2018, and the relationship between Chinese onion yield and nutrient uptake was evaluated using the Quantitative Evaluation of the Fertility of Tropical Soils (QUEFTS) model. The QUEFTS model predicted the linear-parabolic platform curve of the balanced nutrient uptake of Chinese onion and estimated the demand of nitrogen $(N)$, phosphorus (P), and potassium (K) for the potential target yields ranging from $40 \mathrm{t} / \mathrm{ha}$ to $120 \mathrm{t} / \mathrm{ha}$. The nutrients required for the target yield increased linearly before reaching $60 \%$ to $70 \%$ of the potential yield. Nutrient requirements for producing $1 \mathrm{t}$ of Chinese onion were $1.91 \mathrm{~kg} \mathrm{~N}-0.28 \mathrm{~kg} \mathrm{P}-1.71 \mathrm{~kg} \mathrm{~K}$. The corresponding nutrient internal efficiency (IE, yield per unit nutrient uptake) was $524.6 \mathrm{~kg} / \mathrm{kg}, 3585.7 \mathrm{~kg} / \mathrm{kg}$, and 584.3 $\mathrm{kg} / \mathrm{kg}$ for $\mathrm{N}, \mathrm{P}$ and $\mathrm{K}$, respectively. Subsequently, a nutrition decision-making software, Nutrient Expert (NE), for the Chinese onion was developed based on the improved QUEFTS model. Field verification studies for NE fertilizer recommendation were conducted in multiple Chinese onion growing plots for 2 consecutive years. Results showed that the QUEFTS model can be used to accurately estimate the nutrient requirements for Chinese onion within a defined range of target yield.
\end{abstract}

Chinese onion (Allium fistulosum L. var. giganteum Makino) is an important perennial herbaceous plant in Asian countries and is widely grown in the Far East (Ford-Lloyd and Armstrong, 1993), especially in China,

Received for publication 27 Aug. 2021. Accepted for publication 1 Nov. 2021.

Published online 17 January 2022.

This research was supported by the National Key Research \& Development Program of China (No. 2016YFD0200100).

R.C. is the corresponding author. E-mail: rongzongcui@163.com.

This is an open access article distributed under the CC BY-NC-ND license (https://creativecommons. org/licenses/by-nc-nd/4.0/).
Japan and Korea (Feng and Liu, 2011). It is usually used in cooking as a seasoning vegetable that almost every family in China must consume (Aoyama and Yamamoto, 2007; Kim 2010). Chinese onion is also an important raw material for many food processing products (Wang et al., 2005). In China the growing area of Chinese onion reaches 500,000 ha (Wang et al., 2019), with an annual yield of more than 21 million tons (Lian et al., 2020) and roughly $15 \mathrm{~kg}$ per capita.

During 2002 to 2016, the total yield of Chinese onion in China increased by $52.2 \%$ (National Agriculture Ministry, 2002-2016). Fertilizer application plays an important role in increasing the yield of Chinese onion. However, current nutrient management usually does not meet the demand for Chinese onion, and irrational, excessive, and unitary fertilization are widespread (Dong et al., 2014; Xu et al., 2013b). Unscientific fertilization not only leads to the reduction of yields and quality of Chinese onion but also results in the deterioration of the ecological environment as a result of poor nutrient utilization efficiency (Zhu and Jin, 2013), which restricts the sustainable development of Chinese onion industry. Therefore, precise nutrient management is particularly important to improve fertilizer utilization efficiency of Chinese onion. It is necessary to establish a scientific fertilizer recommendation approach based on yield response to guide Chinese onion fertilization.

Previous studies on fertilizer recommendation for Chinese onion were mainly based on soil testing and yield target, which could improve yield and nutrient utilization efficiency (Zhang et al., 2012). However, for the farmers who manage large areas with scattered-planted Chinese onion, this soil testbased fertilizer recommendation system is time-consuming and expensive as it requires a process composed of soil sampling, commissioned testing and subsequent fertilizer application based on the experimental results (Huang et al., 2006). Therefore, it is urgent to identify a widely applicable, scientific, and convenient nutrient management and fertilization recommendation method for Chinese onion producers (He et al., 2012).

The QUEFTS model can quantify the nutrient requirements of crops based on the target yield and nutrient uptake (Janssen et al., 1990). This model uses a large amount of data from different sources to analyze the relationship between crop yield and nutrient uptake, which could be universally applicable for fertilizer recommendation (Smaling and Janssen, 1993). The most prominent feature of this model is that it considers the pairwise interactions of $\mathrm{N}, \mathrm{P}$, and $\mathrm{K}$ nutrients. It uses a linear parabolic plateau curve to estimate the best nutrient uptake for different target yields. According to this model, the optimal nutrient uptake curve of nitrogen, phosphorus, and potassium can be calculated based on the boundaries between maximum nutrient accumulation and the maximum nutrient dilution (Dobermann and Cassman, 2002).

The QUEFTS model has been successfully applied and evaluated in rice (Pampolino et al., 2012; Sun et al., 2021; Witt et al., 1999; Xu et al., 2015), corn (Liu et al., 2006; Saïdou et al., 2003; Setiyono et al., 2010; Xu et al., 2013a), wheat (Chuan et al., 2013; Liu et al., 2006; Pathak et al., 2003), rapeseed (Ren et al., 2016), soybean (Yang et al., 2017), peanut (Xie et al., 2020), potato (Xu et al., 2019), watermelon (Kang et al., 2020), and radish (Zhang et al., 2018, 2019) in many countries including China. From the results of previous studies, this model is applicable to different crops, plant growing areas, climates, and soil types. Therefore, it should also be useful to estimate the nutrient requirements of Chinese onion. The purpose of this 
study was to 1) determine the relationship between the nutrient uptake and yield of Chinese onion; 2) estimate the optimal requirements for nitrogen, phosphorus, and potassium in Chinese onion; and 3) use field experiments to verify and evaluate the ability of QUEFTS to simulate nutrient uptake in Chinese onion.

\section{Materials and Methods}

Data source. A Chinese onion database used in this study was derived from two sources: the data compiled based on the academic papers published from 2001 to 2018 (China National Knowledge Infrastructure; $2001 \pm$ 2015. Database: Journals [Internet]; http:// www.cnki.net/) and data from the database of the China project of International Plant Nutrition Institute (IPNI) and projects of Key Research and Development Program. The database includes yields and nutrient uptake under different nutrient treatments at each experiment site to evaluate the extensive nutrient accumulation and dilution conditions in Chinese onion. The experiment sites were located in 15 provinces, cities, and autonomous regions including Shandong, Hebei, Fujian, and Ningxia provinces (Fig. 1). There were great differences in soil physical and chemical properties in different sites (Table 1 ). These areas covered the main soil types and climatic conditions suitable for the cultivation of Chinese onion. The Chinese onion varieties analyzed in this study were commonly planted in these areas.

Data analysis. After data were collected, the distribution of the Chinese onion yields and the uptake and accumulation of nitrogen, phosphorus, and potassium in Chinese onion were analyzed. The maximum nutrient accumulation $(a)$ and maximum nutrient dilution (d) were calculated as the range of IE (Chinese onion yield per unit amount of nutrient uptake), and then the nutritional requirements for Chinese onion were estimated by the QUEFTS model. The following equations were used for the calculations:

IE of nutrients = Chinese onion yield/ amount of nutrient uptake, which indicates the yield per unit amount of nutrient uptake $(\mathrm{N}, \mathrm{P}$, or $\mathrm{K})$ and reflects the effects of nutrient uptake on the yield.

Reciprocal internal efficiency (RIE) = $1000 / \mathrm{IE}$, which indicates the required N, P, and $\mathrm{K}$ uptake to produce $1 \mathrm{t}$ of Chinese onion.

By collecting a large amount of crop nutrient uptake data and using $a$ and $d$ values and the target yield, the optimal balanced requirement of $\mathrm{N}, \mathrm{P}$, and $\mathrm{K}$ for different target yields within the range of potential yield levels can be calculated. The calculation principle of the QUEFTS model has been described in detail previously (Janssen et al., 1990; Smaling and Janssen, 1993).

Field verification. Field trials were conducted in 2019 to 2020 at 23 locations in the main growing region in Shandong Province, China, to verify the agreement of the nutrient absorption value simulated by the QUEFTS model with the field measured value. Field verification also evaluated the effect and feasibility of fertilizer recommendation for Chinese onion by the NE system based on site-specific nutrient management (SSNM) and QUEFTSbased nutrient requirements. The experimental field underwent seven treatments, including farmers' current practice (FP), balanced fertilization based on Nutrient Expert (NE), balanced ST (fertilization recommended by the local agricultural technology department), N nutrient omission based on NE (NE-N), P nutrient omission based on NE (NE-P), K nutrient omission based on NE (NE-K), and NEOM (NE with $30 \%$ of the synthetic $\mathrm{N}$ fertilizer replaced with organic $\mathrm{N}$ fertilizer). NE fertilization rate was 237 to $287 \mathrm{~kg} /$ ha for $\mathrm{N}, 30$ to $90 \mathrm{~kg} / \mathrm{ha}$ for $\mathrm{P}_{2} \mathrm{O}_{5}$, and 70 to $321 \mathrm{~kg} / \mathrm{ha}$ for $\mathrm{K}_{2} \mathrm{O}$. ST fertilization rate was $270 \mathrm{~kg} /$ ha for $\mathrm{N}$, $150 \mathrm{~kg} / \mathrm{ha}$ for $\mathrm{P}_{2} \mathrm{O}_{5}$, and $300 \mathrm{~kg} / \mathrm{ha}$ for $\mathrm{K}_{2} \mathrm{O}$. NE-related treatment and ST treatment provided $\mathrm{N}, \mathrm{P}$, and $\mathrm{K}$ with urea ( $\mathrm{N} 46 \%$ ), heavy superphosphate $\left(\mathrm{P}_{2} \mathrm{O}_{5} 44 \%\right)$, and potassium sulfate $\left(\mathrm{K}_{2} \mathrm{SO}_{4} 50 \%\right)$. The organic fertilizer used local organic fertilizers, including fermented chicken manure (organic matter $45 \%$, $\mathrm{N} 2.65 \%, \mathrm{P}_{2} \mathrm{O}_{5} 0.89 \%, \mathrm{~K}_{2} \mathrm{O} 1.64 \%$ ) and commercial organic fertilizers (organic matter $30 \%, \mathrm{~N} 1.54 \%, \mathrm{P}_{2} \mathrm{O}_{5} 1.47 \%, \mathrm{~K}_{2} \mathrm{O} 2.35 \%$ ). Fertilizer was applied four times during the growth period; basal fertilizer was applied during the planting period; and three top dressings were applied in the early, middle, and late stages of pseudo stem growth. The ratios of $\mathrm{N}$, $\mathrm{P}$, and $\mathrm{K}$ in the four fertilizations were 20:25:25:30, 60:20:10:10, 20:25:25:30, respectively. Organic fertilizer was used as base fertilizer. The fertilizer used in FP treatment was blended fertilizer or compound fertilizer, and the amount was $135-402 \mathrm{~kg} / \mathrm{ha} \mathrm{N}, 75-390 \mathrm{~kg} /$ ha $\mathrm{P}_{2} \mathrm{O}_{5}$, and $60-384 \mathrm{~kg} / \mathrm{ha} \mathrm{K}_{2} \mathrm{O}$. No dedicated plot was set up for FP but followed the farmers' current practice. The area of each remaining treatment was $30 \mathrm{~m}^{2}$. No duplicate treatment was carried out at the same farmer's plot, and the farmer chose how to manage the field. The onion seedlings were planted in late June for all experimental field and harvested in early November of the same year. NE-related and ST treatments were all harvested, and only

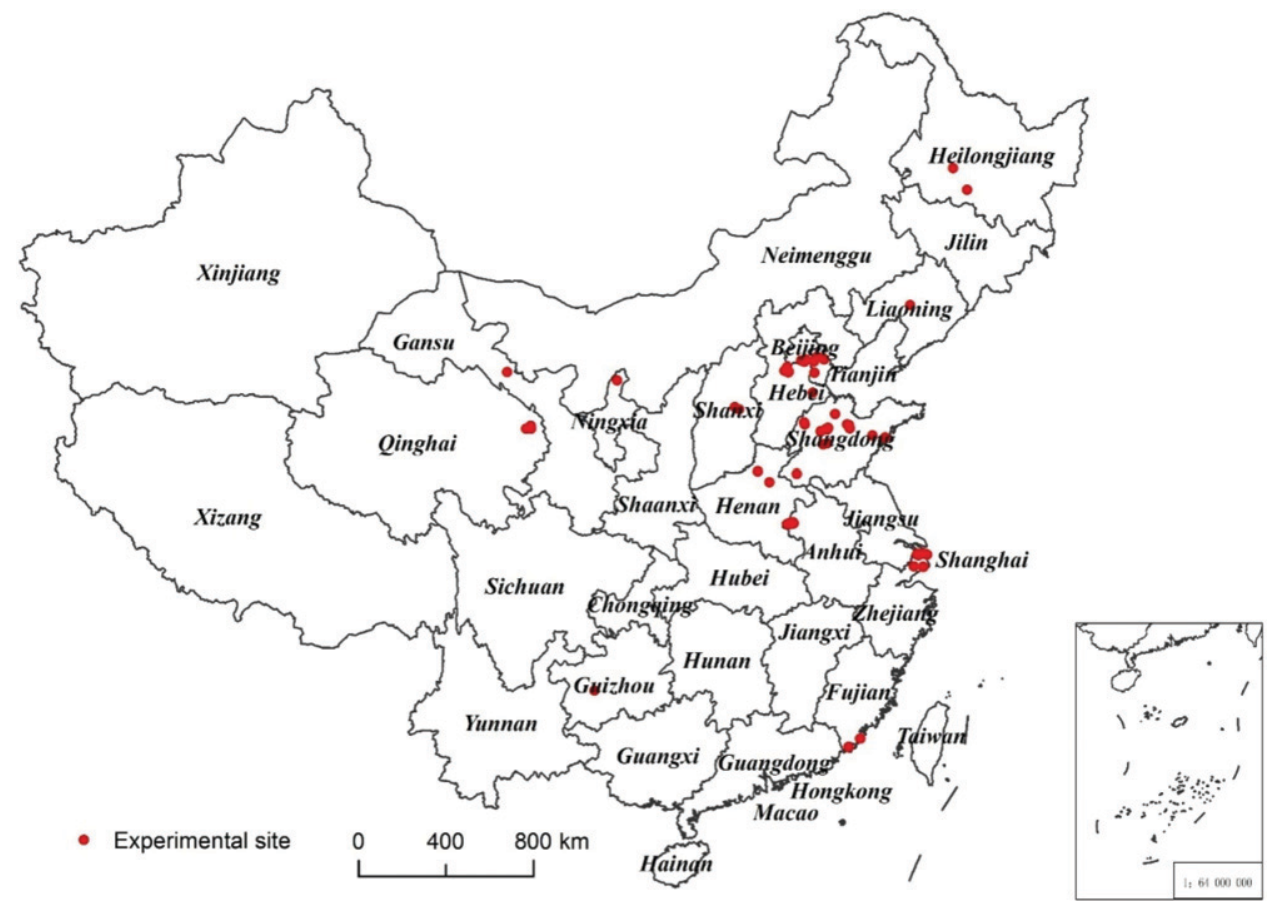

Fig. 1. Distribution of the experimental sites. 
Table 1. Physical and chemical properties of soil in field experiment.

\begin{tabular}{lccccc}
\hline Parameter & $\mathrm{pH}$ & Organic matter $(\mathrm{g} / \mathrm{kg})$ & Alkali-hydrolyzable N $(\mathrm{mg} / \mathrm{kg})$ & $\mathrm{Olsen} \mathrm{P}(\mathrm{mg} / \mathrm{kg})$ & $\mathrm{NH} / \mathrm{OAc}-\mathrm{K}(\mathrm{mg} / \mathrm{kg})$ \\
\hline Range & $7.7 \pm 0.5$ & $16.8 \pm 3.9$ & $88.8 \pm 36.9$ & $65 \pm 39.3$ & $154.3 \pm 78.4$ \\
\hline
\end{tabular}

$30 \mathrm{~m}^{2}$ of the FP treatment was harvested for this study. Five uniformly growing Chinese onions were collected from each treatment plot and transferred back to the laboratory. They were rinsed with distilled water, and the water on the surface of the plants was removed with filter paper. The Chinese onions were chopped into small pieces, heated at $105^{\circ} \mathrm{C}$ for $30 \mathrm{~min}$, and further dried at $70^{\circ} \mathrm{C}$ to constant weight, followed by calculating the moisture content. The total nitrogen, phosphorus, and potassium contents in the dried samples were determined by the Kjeldahl method, the vanadium molybdenum yellow colorimetric method, and the flame photometric method, respectively, after digested with $\mathrm{H}_{2} \mathrm{SO}_{4}-\mathrm{H}_{2} \mathrm{O}_{2}$.

Three statistics were used to evaluate the consistency between the simulated and measured values of nutrient uptake, including mean bias error (MBE), Nash-Sutcliffe efficiency (NSE), and normalized root mean square error (nRMSE) using the following formula where $S_{i}$ and $M_{i}$ are the simulated values and the measured values, respectively, $n$ is the number of simulated or measured values, $M_{a v g}$ is the average of the measured values, and $i$ is the number from 1 to $\mathrm{n}$.

$$
\begin{gathered}
M B E=\frac{\sum_{i=1}^{n}\left(S_{i}-M_{i}\right)}{n} \\
N S E=1-\frac{\sum_{i=1}^{n}\left(S_{i}-M_{i}\right)^{2}}{\sum_{i=1}^{n}\left(M_{i}-M_{a v g}\right)^{2}} \\
n R M S E=\frac{\sqrt{\sum_{i=1}^{n}\left(S_{i}-M_{i}\right)^{2} / n}}{M_{\text {avg }}} \times 100 \%
\end{gathered}
$$

MBE is the average error. When MBE > 0 , it indicates that the simulated value is greater than the measured value; when $\mathrm{MBE}$
$<0$, it indicates that the simulated value is less than the measured value (Yang et al., 2000). The NSE value range is $\infty<\mathrm{EF} \leq 1$, which is a dimensionless statistical evaluation index. In the range of $0<\mathrm{NSE} \leq 1$, large NSE value indicates that the simulated results are highly reliable. When NSE $<0$, it indicates poor simulation performance (Moriasi 2007; Schaefli and Gupta, 2007). nRMSE is unbounded and has no unit. When nRMSE $>$ $30 \%$, it indicates that the model simulation performance is poor; when $20 \%<\mathrm{nRMSE}$ $\leq 30 \%$, the model simulation performance is medium; when $10 \%<$ nRMSE $\leq 20 \%$, the model simulation performance is good; when nRMSE $\leq 10 \%$, it means that the model has excellent simulation performance (Liu et al., 2013).

\section{Results}

Distribution of Chinese onion yield. Stem is the main edible part of Chinese onion, but the economic yield is calculated based on the entire plant of Chinese onion. Therefore, the crop harvest index used in the model in this study is 1, which is different from the QUEFTS used for other crops. The results showed that the yield of Chinese onion $(\mathrm{n}=$ 1030) ranged from 15.1 to 150.0 t/ha (Fig. 2). Due to differences in the environment, climate, variety and planting habits in different regions, the yield of Chinese onion mainly ranged from 30 to $90 \mathrm{t} / \mathrm{ha}$, accounting for $68.6 \%$ of the total number of samples.

Nutrient uptake by Chinese onion. The average contents of $\mathrm{N}, \mathrm{P}$, and $\mathrm{K}$ in the plant of Chinese onion (dry matter base) was $23.71,3.55$, and $20.94 \mathrm{~g} / \mathrm{kg}$, respectively. Due to the differences in planting environ- ment, varieties of Chinese onion and management practices in different regions, the nutrient contents in plants varied greatly, especially for the contents of $\mathrm{K}$ ranging from 9.96 to $53.50 \mathrm{~g} / \mathrm{kg}$. The highest content of $\mathrm{K}$ was more than 5 times of the lowest content (Table 1). The average accumulation of $\mathrm{N}, \mathrm{P}$, and $\mathrm{K}$ in Chinese onion was $130.85,18.49$, and $113.59 \mathrm{~kg} / \mathrm{ha}$, respectively (Table 2). Similarly, the nutrient accumulation also varied greatly in different regions.

$I E$ and RIE. The average IE of $\mathrm{N}, \mathrm{P}$, and $\mathrm{K}$ was 524,3629 , and $639 \mathrm{~kg} / \mathrm{kg}$, respectively. The average RIE (nutrients uptake per ton of Chinese onion yield) of $\mathrm{N}, \mathrm{P}$, and $\mathrm{K}$ was $2.00,0.29$, and $1.84 \mathrm{~kg} / \mathrm{t}$, respectively (Table 3 ). The requirement for $\mathrm{N}$ and $\mathrm{K}$ was similar, which was significantly higher than the requirement for $\mathrm{P}$. The requirement for $\mathrm{P}$ was only $\approx 15 \%$ of that for $\mathrm{N}$ and $\mathrm{K}$.

Application of the QUEFTS model to estimate the nutrient requirements of Chinese onion. On the basis of previous studies using QUEFTS for other crops (Chuan et al., 2013; Kang et al., 2020; Liu et al., 2006; Pampolino et al., 2012; Pathak et al., 2003; Ren et al., 2016; Saïdou et al., 2003; Setiyono et al., 2010; Sun et al., 2021; Witt et al., 1999; Xie et al., 2020; Xu et al., 2013a, 2015, 2019; Yang et al., 2017; Zhang et al., 2018, 2019), the $a$ and $d$ values with the corresponding $2.5 \%$ of the upper and lower IE values removed were used as the parameters of the QUEFTS to estimate the nutrient requirements for Chinese onion. The results showed that $a$ values of $\mathrm{N}, \mathrm{P}$, and $\mathrm{K}$ were 308.9 , 782.7 , and $2004.4 \mathrm{~kg} / \mathrm{kg}$, respectively. The $d$ values of $\mathrm{N}, \mathrm{P}$, and $\mathrm{K}$ were $5634.7,278.4$, and $1123.8 \mathrm{~kg} / \mathrm{kg}$, respectively. The QUEFTS model was used to simulate the optimal

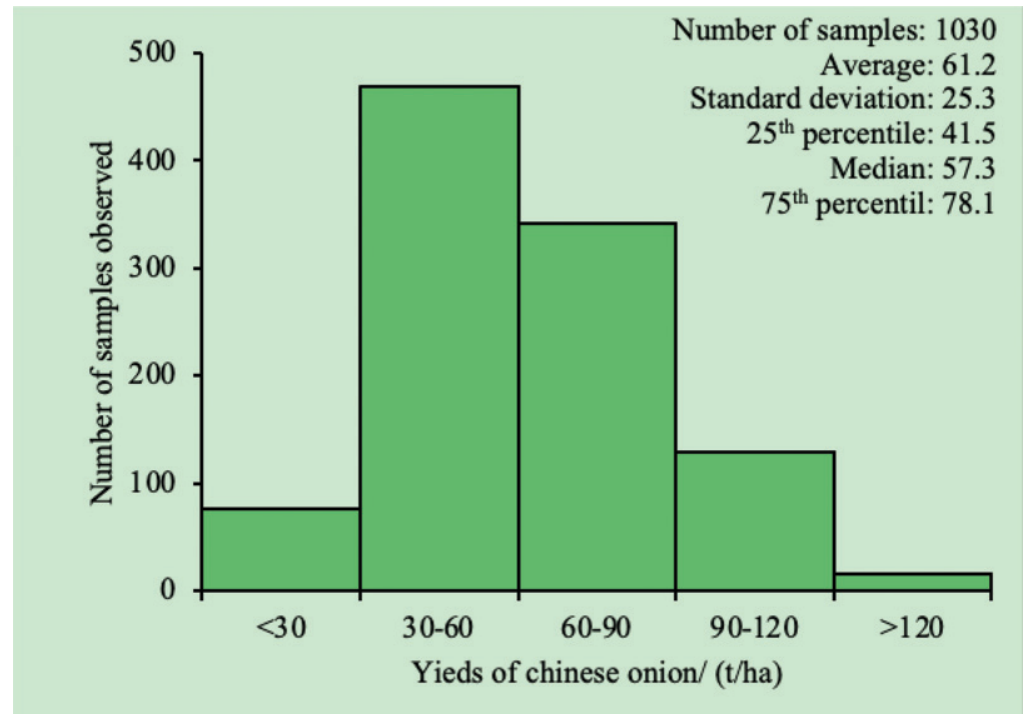

Fig. 2. Distribution of Chinese onion yields. 

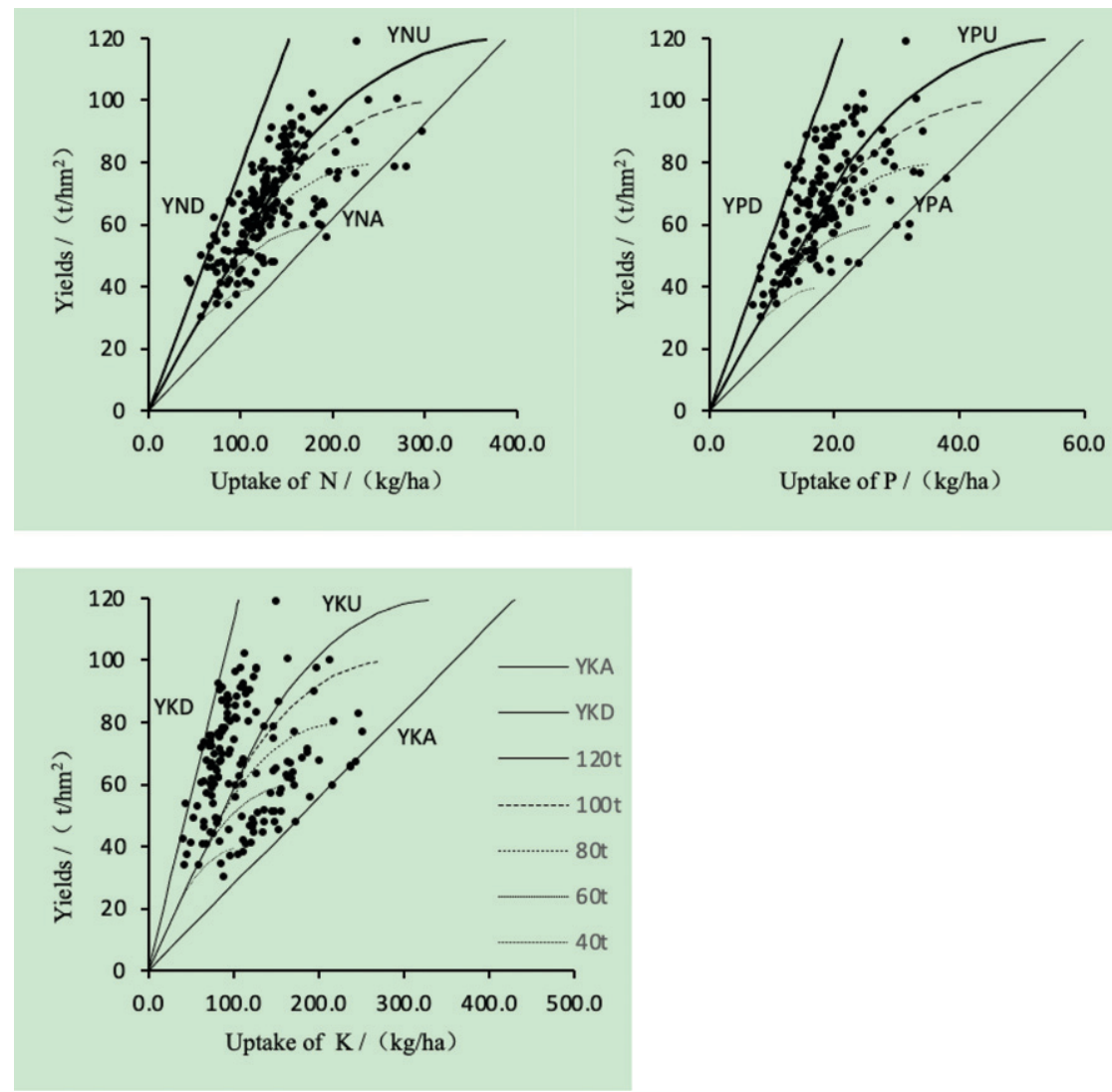

Fig. 3. The optimal nutrient requirements of Chinese onion under different potential yields simulated by the QUEFTS model. YND, YNA, and YNU represent the maximum dilution, maximum accumulation, and balanced uptake of $\mathrm{N}$ in above-ground plant with specific target yield. YPD, YPA, and YPU represent the maximum dilution, maximum accumulation, and balanced uptake of $\mathrm{P}$ in above-ground plant with specific target yield. YKD, YKA, and YKU represent the maximum dilution, maximum accumulation and balanced uptake of $\mathrm{K}$ in above-ground plant with specific target yield. The yield potential of Chinese onion ranges from 40 to $120 \mathrm{t} / \mathrm{ha}$.

above-ground nutrient uptake requirements for the $\mathrm{N}, \mathrm{P}$, and $\mathrm{K}$ under different target yields of Chinese onion ranging from 40 to $120 \mathrm{t} /$ ha (Fig. 3). The simulation results showed that no matter what the potential yield was, when the yield reached $60 \%$ to $70 \%$ of the potential yield, the nutrient requirements for producing $1 \mathrm{t}$ of Chinese onion yield were consistent. The nutrient required for the target yield before reaching $60 \%$ to $70 \%$ of the potential yield increased linearly. To achieve $1 \mathrm{t}$ of Chinese onion yield, $1.91 \mathrm{~kg}$ of $\mathrm{N}, 0.28 \mathrm{~kg}$ of $\mathrm{P}$, and $1.71 \mathrm{~kg}$ of $\mathrm{K}$ were required, and the corresponding IE values were $524.6,3585.7$, and $584.3 \mathrm{~kg} / \mathrm{kg}$ for $\mathrm{N}, \mathrm{P}$, and $\mathrm{K}$, respectively (Table 4). To maintain soil fertility, the nutrients removal by harvested Chinese onion must be returned to the soil. The estimation of the nutrient uptake in Chinese onion can provide guidance for rational rate of fertilization. On the basis of the target yield and yield response, and comprehensive consideration of nutrient balance, the recommended amount of $\mathrm{N}, \mathrm{P}$, and $\mathrm{K}$ for different target yields can be estimated. Subsequently, a computer software based on the improved QUEFTS-NE was developed for nutrition decision-making. This software can evaluate the supply of soil nutrients and yield potential and recommend scientific fertilization program based on the climatic characteristics and soil fertility level of the growing plot, as well as field agronomic management habits.

QUEFTS model validation. From 2019 to 2020, verification studies on QUEFTS model recommendation in Chinese onion were carried out on multiple fields in the main Chinese onion growing areas. Results showed that the calculated MBE values for plant $\mathrm{N}$,
$\mathrm{P}$, and $\mathrm{K}$ uptake were $-20.1,-0.6$, and -23.2 $\mathrm{kg} / \mathrm{ha}$, respectively, which were all less than 0 , indicating that the overall simulated values are less than the measured values (Fig. 4). The NSE values of plant N, P, and K uptakes were $0.69,0.82$, and 0.32 , respectively, which are all greater than 0 , indicating that the model has reliable simulation performance. The nRMSE values of plant $\mathrm{N}, \mathrm{P}$, and $\mathrm{K}$ uptakes were $20.3 \%, 13.6 \%$, and $27.0 \%$, respectively, which were all less than $30 \%$. Although there were some variabilities between the simulated and measured nutrient uptake values, in general, the simulated plant phosphorus uptake value was in the highest agreement with the measured value, followed by nitrogen, whereas the simulated potassium uptake value was in a moderate agreement with the measured value. Field validation results showed that the QUEFTS model can

Table 2. Characteristics of nutrient uptake by Chinese onion.

\begin{tabular}{|c|c|c|c|c|c|c|c|c|c|}
\hline Parameter & Unit & $\mathrm{n}$ & Mean & SD & Minimum & $25 \% \mathrm{Q}$ & Median & $75 \% \mathrm{Q}$ & Maximum \\
\hline $\mathrm{Nc}$ & $\mathrm{g} / \mathrm{kg}$ & 160 & 23.43 & 4.43 & 13.83 & 20.56 & 23.36 & 26.10 & 41.64 \\
\hline $\mathrm{Pc}$ & $\mathrm{g} / \mathrm{kg}$ & 159 & 3.38 & 0.87 & 1.89 & 2.62 & 3.33 & 4.10 & 6.00 \\
\hline $\mathrm{Kc}$ & $\mathrm{g} / \mathrm{kg}$ & 134 & 21.50 & 10.93 & 9.96 & 13.87 & 15.69 & 31.48 & 53.50 \\
\hline Uptake P & $\mathrm{kg} / \mathrm{ha}$ & 168 & 18.49 & 5.84 & 7.09 & 14.28 & 18.03 & 21.76 & 37.85 \\
\hline Uptake K & $\mathrm{kg} / \mathrm{ha}$ & 153 & 113.59 & 45.69 & 40.42 & 81.28 & 102.70 & 144.07 & 250.79 \\
\hline
\end{tabular}

$\mathrm{n}=$ number of observations; $\mathrm{Q}=$ quartile; $\mathrm{Nc}=$ percentage of nitrogen in the dry plant. 
Table 3. Internal efficiency (IE) and reciprocal IE (RIE) of N, P, and $\mathrm{K}$ for Chinese onion.

\begin{tabular}{|c|c|c|c|c|c|c|c|c|c|}
\hline Parameter & Unit & $\mathrm{n}$ & Mean & SD & Minimum & $25 \% \mathrm{Q}$ & Median & $75 \% \mathrm{Q}$ & Maximum \\
\hline$\overline{\mathrm{IE}-\mathrm{N}}$ & $\mathrm{kg} / \mathrm{kg}$ & 208 & 524 & 113 & 282 & 463 & 528 & 577 & 992 \\
\hline IE-P & $\mathrm{kg} / \mathrm{kg}$ & 184 & 3692 & 882 & 1761 & 3154 & 3615 & 4299 & 6263 \\
\hline IE-K & $\mathrm{kg} / \mathrm{kg}$ & 169 & 639 & 245 & 277 & 389 & 604 & 836 & 1221 \\
\hline RIE-N & $\mathrm{kg} / \mathrm{t}$ & 208 & 2.00 & 0.46 & 1.01 & 1.73 & 1.89 & 2.16 & 3.55 \\
\hline RIE-P & $\mathrm{kg} / \mathrm{t}$ & 184 & 0.29 & 0.08 & 0.16 & 0.23 & 0.28 & 0.32 & 0.57 \\
\hline RIE-K & $\mathrm{kg} / \mathrm{t}$ & 169 & 1.84 & 0.77 & 0.82 & 1.20 & 1.65 & 2.57 & 3.60 \\
\hline
\end{tabular}

$\mathrm{n}=$ number of observations; $\mathrm{Q}=$ quartile.

Table 4. Simulation of internal efficiency (IE) and nutrient uptake by QUEFTS (potential yield was set at $120 \mathrm{t} / \mathrm{ha})$.

\begin{tabular}{|c|c|c|c|c|c|c|}
\hline \multirow[b]{2}{*}{ Yield $\left(\mathrm{t} / \mathrm{hm}^{2}\right)$} & \multicolumn{3}{|c|}{ IE $(\mathrm{kg} / \mathrm{kg})$} & \multicolumn{3}{|c|}{ Nutrient uptake $(\mathrm{kg} / \mathrm{t})$} \\
\hline & $\mathrm{N}$ & $\mathrm{P}$ & $\mathrm{K}$ & $\mathrm{N}$ & $\mathrm{P}$ & $\mathrm{K}$ \\
\hline 0 & 0 & 0 & 0 & 0 & 0 & 0 \\
\hline 10 & 524.6 & 3585.7 & 584.3 & 1.91 & 0.28 & 1.71 \\
\hline 20 & 524.6 & 3585.7 & 584.3 & 1.91 & 0.28 & 1.71 \\
\hline 30 & 524.6 & 3585.7 & 584.3 & 1.91 & 0.28 & 1.71 \\
\hline 40 & 524.6 & 3585.7 & 584.3 & 1.91 & 0.28 & 1.71 \\
\hline 50 & 524.6 & 3585.7 & 584.3 & 1.91 & 0.28 & 1.71 \\
\hline 60 & 524.6 & 3585.7 & 584.3 & 1.91 & 0.28 & 1.71 \\
\hline 70 & 524.6 & 3585.7 & 584.3 & 1.91 & 0.28 & 1.71 \\
\hline 80 & 522.2 & 3568.7 & 581.5 & 1.92 & 0.28 & 1.72 \\
\hline 90 & 494.9 & 3382.8 & 551.2 & 2.02 & 0.30 & 1.81 \\
\hline 100 & 462.0 & 3157.3 & 514.5 & 2.16 & 0.32 & 1.94 \\
\hline 110 & 417.7 & 2855.0 & 465.2 & 2.39 & 0.35 & 2.15 \\
\hline 120 & 400.5 & 58.6 & 359.7 & 3.34 & 0.49 & 3.00 \\
\hline
\end{tabular}

QUEFTS = Quantitative Evaluation of the Fertility of Tropical Soils model.

estimate the nutrient requirements for a defined target yield and be used as a guiding parameter for fertilizer recommendation. The $\mathrm{NE}$ system can provide relatively accurate fertilizer recommendations based on the agronomic parameters of Chinese onionin specific production conditions and field agronomic management habits. Compared with the FP and ST, NE recommendation is a dynamic nutrient management strategy. It does not intend to reduce or increase fertilizer application. In contrast, it intends to optimize nutrient supply, balance soil nutrients, and maintain soil fertility to avoid ecological and environmental risks and reduction of Chinese onion yield and economic returns caused by excessive or insufficient nutrient input.

\section{Discussion}

The QUEFTS model analyzes the correlation between yield and nutrient uptake based on a large number of crop yield and nutrient uptake data from different sources of experimental sites, and thus it could be universally applicable (Smaling and Janssen, 1993). However, Chinese onion is obviously different from other previously studied crops. Although Chinese onion belongs to angiosperms, the proportions of various parts of the plant have changed greatly during the evolution process. The harvested plants are mainly divided into onion stem and onion leaf. The onion stem part is also called the "pseudostem," which is actually the sheath part of the onion leaf (Chinese Agricultural Encyclopedia Editor-In-Chief Committee, Vegetable Volume Editing Committee, 1990). Both onion stem and onion leaves are edible and are regarded as economic yield. Therefore, the harvest index of Chinese onion in the study was 1 , whereas other crops such as corn, peanuts, radishes, and watermelons are divided into economic and noneconomic yield, and the harvest index is 0.18 to 0.82 (Kang et al., 2020; Xie et al., 2020; Xu et al., 2015; Zhang et al., 2019). For Chinese onion with harvest index of 1 , it is more convenient to use the QUEFTS model to simulate the nutrient requirements and the simulation is also more accurate, which was verified in field experiments in this study.

Simulations of nutrient requirements by QUEFTS model have been carried out for many crops, including corn (Xu et al., 2013a), wheat (Chuan et al., 2013), rice (Xu et al., 2015), rapeseed (Ren et al., 2016), sweetpotato (Kumar et al., 2016), soybean (Yang et al., 2017), peanut (Xie et al., 2020), potato (Xu et al., 2019), watermelon (Kang et al., 2020), carrot (Zhang et al., 2019), and sunflower (Duan et al., 2020). In these studies, the a value and $\mathrm{d}$ values were determined similarly by removing the upper and lower $2.5 \%, 5.0 \%$, and $7.5 \%$ of the IE values. Results indicated that there is little difference in the nutrient uptake curve calculated by the a and d values with $2.5 \%, 5.0 \%$, and $7.5 \%$ cutoff. Because the $2.5 \%$ cutoff allowed a wide range of IE values, it was used in the determination of the a and $d$ values of the QUEFTS model for nutrient uptake simulation in this study.

The field verification studies indicated that most of the $\mathrm{N}$ uptake data points at the Anqiu and Qingzhou experimental sites were concentrated in the right area of the figure and below the 1:1 diagonal, which reflects the excessive $\mathrm{N}$ uptake by Chinese onion in this area. This is due to the local continuous application of high nitrogen fertilizers in the growing areas. The input of nitrogen fertilizer by farmers for a single production season reaches $450 \mathrm{~kg} / \mathrm{ha}$ (Zhang et al., 2020), which is significantly higher than that in Zhangqiu and other areas (Zhang et al., 2012). Excessive and long-term nitrogen application can cause accumulation of residual nitrogen in the soil, which makes Chinese onion extravagantly uptake nitrogen nutrients. The $\mathrm{K}$ uptake data points at the experimental sites in Laoling, Dong'e, and Caoxian were distributed at the bottom of the 1:1 diagonal line, reflecting the excessive $\mathrm{K}$ uptake by Chinese onion in this area. This is possibly due to the soil type and higher potassium fertilizer application in the experimental sites. These experimental sites are located in the floodplain of the Yellow River. Particularly, the Caoxian experimental site is located in the old course of the Yellow River (Caoxian Local Chronicles Compilation Committee, 2013) and the soil type is the fluvo-aquic soil developed from the sediments of the Yellow River, which is rich in potassium-containing minerals such as hydromica (State Soil Survey Service of China, 1998). At the same time, the experimental site was planted with vegetables for many years, and long-term high-volume potassium fertilizer application resulted in excessive uptake and accumulation of potassium nutrients by Chinese onion.

This study was based on procedures and experiences of previous studies using the QUEFTS model in other crops to simulate nutrient uptake and requirement of Chinese onion. Previous studies on Chinese onion were limited and particularly lack of data on nutrient uptake and accumulation. Although we have tried our best to collect and analyze the published literature to achieve good simulation effect, the results would be more reliable if much more data are available. Therefore, further studies in the future need to collect more data to revise, improve, and optimize Chinese onion NE system for more scientific and accurate fertilizer recommendation.

\section{Conclusion}

This is the first time that QUEFTS model was used to simulate the optimal nutrient requirements for Chinese onion, which provides scientific foundation for further optimizing the management and improving fertilizer application. Large 

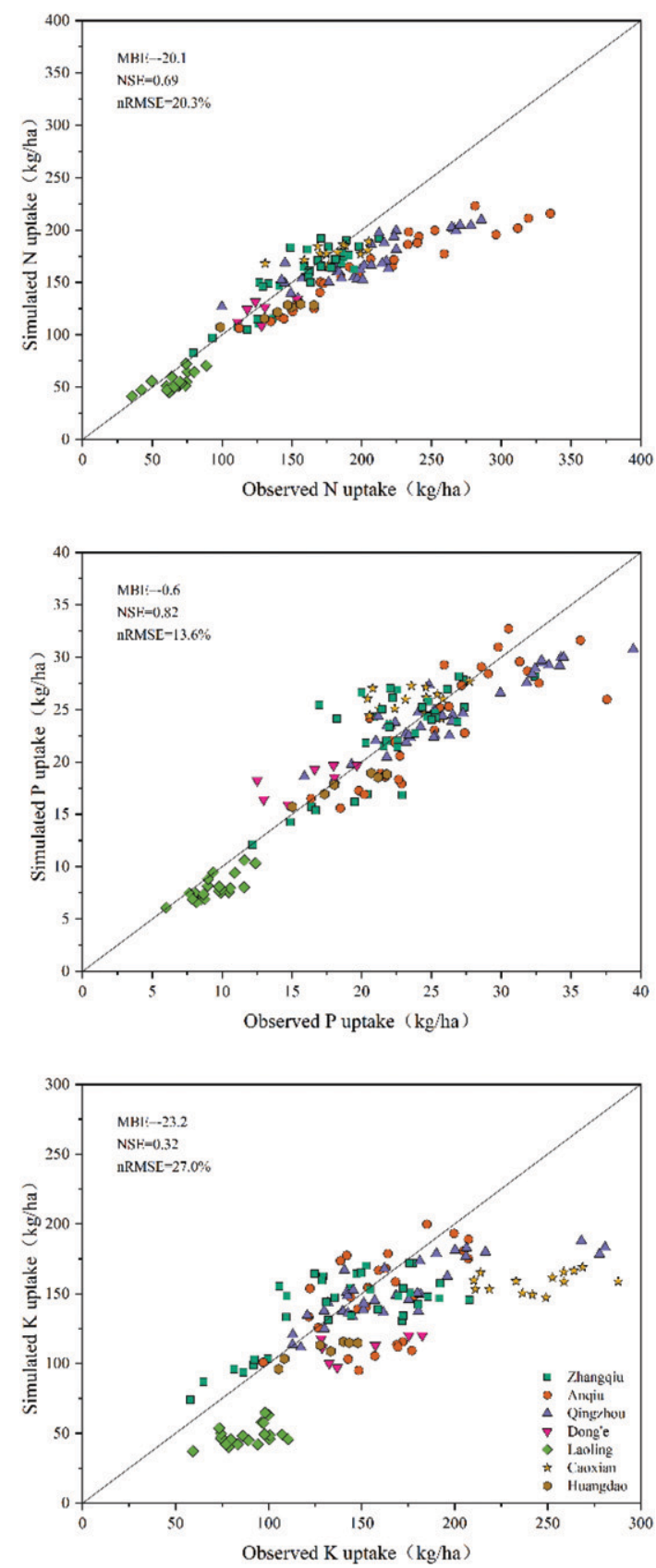

Fig. 4. Comparison of simulated and measured N, P, and K uptake by Chinese onion (2019-20). Observed N, P, and K uptake. Simulated N, P, and K uptake.

data sets from various Chinese onion growing areas were used to estimate balanced nutrient requirements based on the QUEFTS model. Regardless of the potential yield of Chinese onion, the uptake of $\mathrm{N}$, $\mathrm{P}$, and $\mathrm{K}$ increases linearly with the increases of the yield, until it reaches $\approx 60 \%$ to $70 \%$ of the potential yield. To produce $1000 \mathrm{~kg}$ of Chinese onion, aboveground plants must uptake $1.91 \mathrm{~kg}$ of $\mathrm{N}$, $0.28 \mathrm{~kg}$ of $\mathrm{P}$, and $1.71 \mathrm{~kg}$ of $\mathrm{K}(\mathrm{N}-\mathrm{P}-\mathrm{K}=$ $7: 1: 6)$. Multiple field experiments showed that the NE system based on the improved QUEFTS model is reliable and feasible as a fertilizer recommendations. Therefore, the QUEFTS model can reliably estimate
$\mathrm{N}$, P, and $\mathrm{K}$ uptake by Chinese onion for fertilizer recommendation.

\section{Literature Cited}

Aoyama, S. and Y. Yamamoto. 2007. Antioxidant activity and flavonoid content of Welsh onion (Allium fistulosum) and the effect of thermal treatment. Food Sci. Technol. Res. 13(1): 67-72, https://doi.org/10.3136/fstr.13.67.

Caoxian Local Chronicles Compilation Committee. 2013. Caoxian chronicles 1986-2009. Fangzhi Press, Beijing, China.

Chinese Agricultural Encyclopedia Editor-In-Chief Committee, Vegetable Volume Editing Committee. 1990. China agricultural encyclopedia vegetable volume. Agricultural Publishing Press, Beijing, China, p. 55-56.
Chuan, L.M., P. He, J.Y. Jin, S.T. Li, C.A. Grant, X.P. Xu, S.J. Qiu, S.C. Zhao, and W. Zhou. 2013. Estimating nutrient uptake requirements for wheat in China. Field Crops Res. 146:96-104, https://doi.org/10.1016/j.fcr.2013.02.015.

Dobermann, A. and K.G. Cassman. 2002. Plant nutrient management for enhanced productivity in intensive grain production systems of the United States and Asia. Plant Soil 247(1): 153-175, https://doi.org/10.1007/978-94-017 -2789-1_12.

Dong, F., L. Gao, C. Wang, W. Chen, and Y. Chen. 2014. Effects of Ca, Mg, S, and Si fertilizers' application rate on yield of welsh onion. Soils Fertil. Sci. China 43(1):53-56.

Duan, Y., J. Zhang, J. Liang, H. An, H. Li, and B. Wang. 2020. Using QUEFTS to calculate the parameters needed for fertilizer recommendation 
of sunflower. J. Plant Nutr. Fertilizers 26(7):1349-1359, https://doi.org/10.11674/zwyf. 19427.

Feng, X. and W. Liu. 2011. Variation of quercetin content in different tissues of Welsh onion (Allium fistulosum L.). Afr. J. Agr. Res. 6(26):5675-5679, https://doi.org/10.5897/AJAR10.1141.

Ford-Lloyd, B.V. and S.J. Armstrong. 1993. Welsh onion Allium fistulosum L., p. 51-58. In: G. Kalloo and B.O. Bergh (eds.). Genetic improvement of vegetable crops. Pergamon Press, https:// doi.org/10.1016/B978-0-08-040826-2.50009-6.

He, P., J.Y. Jin, M.F. Pampolino, and A. Johnston. 2012. Approach and decision support system based on crop yield response and agronomic efficiency. Plant Nutr. Fertilizer Sci. 18(2):499-505, https://doi.org/10.11674/zwyf.2012.11248.

Huang, S.W., J.Y. Jin, L.P. Yang, and Y.L. Bai. 2006. Spatial variability of soil nutrients and influencing factors in a vegetable production area of Hebei Province in China. Nutr. Cycl. Agroecosyst. 75:201-212, https://doi.org/10.1007/s10705006-9027-9.

Janssen, B.H., F.C.T. Guiking, D. van der Eijk, E.M.A. Smaling, J. Wolf, and H. van Reuler. 1990. A system for quantitative evaluation of the fertility of tropical soils (QUEFTS). Geoderma 46:299-318, https://doi.org/10.1016/ 0016-7061(90)90021-Z.

Kang, F., Z. Wang, H. Xiong, Y. Li, Y. Wang, Z. Fan, H. Zhao, D. Kuang, Z. Chen, J. Wang, X. He, X. Chen, X. Shi, and Y. Zhang. 2020. Estimation of watermelon nutrient requirements based on the QUEFTS model. Agronomy (Basel) 10(11):1776, https://doi.org/10.3390/ agronomy 10111776 .

Kim, J. 2010. Inhibitory effect of green onion on the growth of Aspergillus parasiticus. Department of Public Health, Keimyung University, Daegu, Republic of Korea, p. 701-704.

Kumar, P., G. Byju, and B.P. Singh. 2016. Application of QUEFTS model for site specific nutrient management of NPK in sweet potato (Ipomoea batatas L. Lam). Commun. Soil Sci. Plant Anal. 47(13):1599-1611, https://doi.org/ 10.1080/00103624.2016.1194989.

Lian, H., Y. Li, Y. Zong, and B. Zhao. 2020. Empirical analysis of price fluctuation characteristics of Allium fistulosum in China. North. Hort. 44(04):153-158, https://doi.org/10.11937/ bfyy. 20190339.

Liu, M.Q., Z.R. Yu, Y.H. Liu, and N.T. Konijn. 2006. Fertilizer requirements for wheat and maize in China: The QUEFTS approach. Nutr. Cycl. Agroecosyst. 74:245-258, https://doi.org/ 10.1007/s10705-006-9002-5.

Liu, S., J.Y. Yang, X.Y. Zhang, C.F. Drury, W.D. Reynolds, and G. Hoogenboom. 2013. Modelling crop yield, soil water content and soil temperature for a soybean-maize rotation under conventional and conservation tillage systems in northeast China. Agr. Water Manage. 123:32-44, https:// doi.org/10.1016/j.agwat.2013.03.001.
Moriasi, D. 2007. Model evaluation guidelines for systematic quantification of accuracy in watershed simulations. Transact. Asabe 50(3):885-900, https://doi.org/10.13031/2013.23153.

National Agriculture Ministry. 2002-2016. Chinese agricultural statistics 2002-2016. The Agriculture Press, Beijing, China.

Pampolino, M.F., C. Witt, J.M. Pasuquin, A. Johnston, and M.J. Fisher. 2012. Development approach and evaluation of the Nutrient Expert software for nutrient management in cereal crops. Comput. Electron. Agr. 88:103-110, https://doi.org/10.1016/j.compag.2012.07.007.

Pathak, H., P.K. Aggarwal, R. Roetter, N. Kalra, S.K. Bandyopadhaya, S. Prasad, and H. Van Keulen. 2003. Modelling the quantitative evaluation of soil nutrient supply nutrient use efficiency and fertilizer requirements of wheat in India. Nutr. Cycl. Agroecosyst. 65:105-113, https://doi.org/10.1023/A:1022177231332.

Ren, T., J. Zou, Y. Wang, X. Li, R. Cong, and J.W. Lu. 2016. Estimating nutrient requirements for winter oilseed rape based on QUEFTS analysis. J. Agr. Sci. 154(03):425-437, https:// doi.org/10.1017/S0021859615000301.

Saïdou, A., B.H. Janssen, and E.J.M. Temminghoff. 2003. Effects of soil properties, mulch and NPK fertilizer on maize yields and nutrient budgets on ferralitic soils in southern Benin. Agr. Ecosyst. Environ. 100:265-273, https:// doi.org/10.1016/S0167-8809(03)00184-1.

Schaefli, B. and H.V. Gupta. 2007. Do Nash values have value? Hydrol. Processes 21(15):20752080, https://doi.org/10.1002/hyp.6825.

Setiyono, T.D., D.T. Walters, K.G. Cassman, C. Witt, and A. Dobermann. 2010. Estimating maize nutrient uptake requirements. Field Crops Res. 118:158-168, https://doi.org/ 10.1016/j.fcr.2010.05.006.

Smaling, E. and B.H. Janssen. 1993. Calibration of QUEFTS, a model predicting nutrient uptake and yields from chemical soil fertility indices. Geoderma 59:21-44, https://doi.org/10.1016/ 0016-7061(93)90060-X.

State Soil Survey Service of China. 1998. Chinese soil. Beijing Agricultural Press, Beijing, China.

Sun, T., X. Yang, S. Tang, K. Han, P. He, and L. $\mathrm{Wu}$. 2021. Genotypic variation in nutrient uptake requirements of rice using the QUEFTS model. Agronomy (Basel) 11(1):26, https:// doi.org/10.3390/agronomy11010026.

Wang, D., J. Gao, and G. Liu. 2005. General situation of Allium crops in China. Acta Hort. 688(688):327-332, https://doi.org/10.17660/ ActaHortic.2005.688.48

Wang, H., Y. Wu, T. Li, J. Zhang, and J. Hou. 2019. Current situation and prospect of research on green Chinese onion planting machinery. J. Chin. Agr. Mech. 40(2):35-39.

Witt, C., A. Dobermann, S. Abdulrachman, H.C. Gines, G.H. Wang, R. Nagarajan, S. Satawatananont, T.T. Son, P.S. Tan, L. Van Tiem, G.C. Simbahan, and D.C. Olk. 1999. Internal nutrient efficiencies of irrigated lowland rice in tropical and subtropical Asia. Field Crops Res. 63:113-138, https://doi.org/10.1016/S0378-42 90(99)00031-3.

Xie, M.M., Z. Wang, X. Xu, and X. Zheng. 2020. Quantitative estimation of the nutrient uptake requirements of peanut. Agronomy (Basel) 10(1):119, https://doi.org/10.3390/agronomy10 010119.

Xu, X.P., P. He, M.F. Pampolino, L.M. Chuan, A.M. Johnston, S.J. Qiu, S.C. Zhao, and W. Zhou. 2013a. Nutrient requirements for maize in China based on QUEFTS analysis. Field Crops Res. 150:115-125, https://doi.org/10.1016/ j.fcr.2013.06.006.

Xu, X.P., J.G. Xie, Y.P. Hou, P. He, M.F. Pampolino, S.C. Zhao, S.J. Qiu, A.M. Johnston, and W. Zhou. 2015. Estimating nutrient uptake requirements for rice in China. Field Crops Res. 180:37-45, https:// doi.org/10.1016/j.fcr.2015.05.008.

Xu, Y., P. He, X. Xu, S.J. Qiu, S. Ullah, Q. Gao, and W. Zhou. 2019. Estimating nutrient uptake requirements for potatoes based on QUEFTS analysis in China. Agron. J. 111(5):2387-2394, https://doi.org/10.2134/agronj2018.09.0572.

Xu, Y., L. Jiang, H. Lin, F. Zheng, D. Tan, J. Shi, and Z. Liu. 2013b. Effects of nitrogen supply on growth and nitrogen nutrition of Chinese onion. Acta Agr. Boreali-Occidentalis Sinica 22(4):102-108.

Yang, F., X. Xu, W. Wang, J. Ma, D. Wei, P. He, M.F. Pampolino, and A.M. Johnston. 2017. Estimating nutrient uptake requirements for soybean using QUEFTS model in China. PLoS One 12(5):e177509, https://doi.org/10.1371/ journal.pone.0177509.

Yang, J., D.J. Greenwood, D.L. Rowell, G.A. Wadsworth, and I.G. Burns. 2000. Statistical methods for evaluating a crop nitrogen simulation model, N_ABLE. Agr. Syst. 64(1):37-53, https://doi.org/10.1016/S0308-521X(00)00010-X.

Zhang, J., P. He, W. Ding, X. Xu, S. Ullah, T. Abbas, C. Ai, M. Li, R. Cui, C. Jin, and W. Zhou. 2019. Estimating nutrient uptake requirements for radish in China based on QUEFTS model. Sci. Rep. 9(1):1-10, https://doi.org/ 10.1038/s41598-019-48149-6.

Zhang, J.J., P. He, X.P. Xu, W.C. Ding, S. Ullah, Y.L. Wang, L.L. Jia, R.Z. Cui, H.T. Wang, and W. Zhou. 2018. Nutrient expert improves nitrogen efficiency and environmental benefits for winter wheat in China. Agron. J. 110(2):696, https://doi.org/10.2134/agronj2017.05.0291.

Zhang, S.Y., T. Li, and B. Wu. 2012. Theory and practice of Zhangqiu soil testing and fertilization. Shan Dong University Press, Jinan, China.

Zhang, X., L. Zhang, D. Tan, T. Liu, and J. Gao. 2020. Analysis on the effect of replacing chemical fertilizer with green onion bio-organic fertilizer. Mod. Agr. 527(5):40-41, https://doi.org/ 10.3969/j.issn.1008-0708.2020.05.022.

Zhu, Z. and J. Jin. 2013. Fertilizer use and food security in China. Plant Nutr. Fert. Sci. 19(2):259-273, https://doi.org/10.11674/zwyf.2013.0201. 